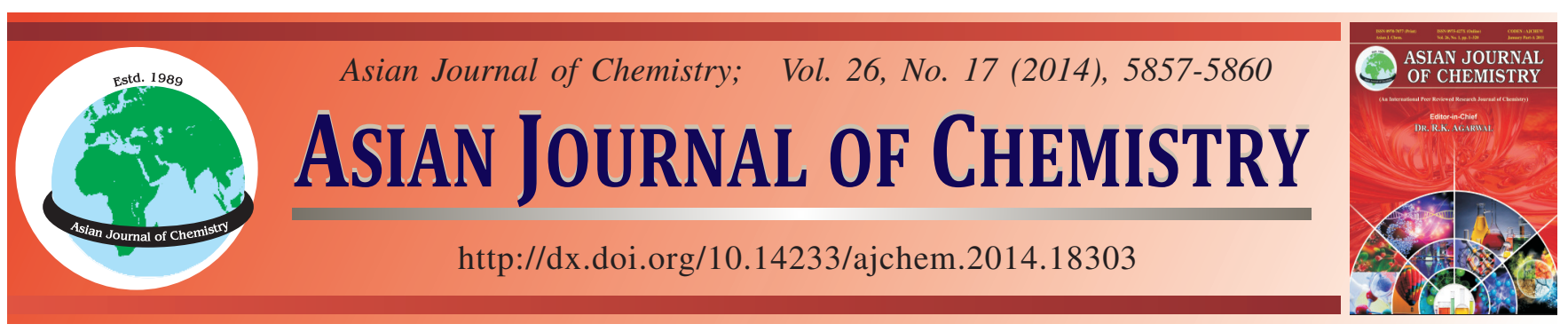

\title{
Shear Deformation Analysis of Fabric Prepreg through Picture-Frame Test and Finite Element Method $\dagger$
}

\author{
Guo Chang Lin*, Xue Bo Yuan and Hui Feng Tan
}

Harbin Institute of Technology, Harbin, P.R. China

*Corresponding author: E-mail: lingc@ @it.edu.com

Based on picture-frame test and finite element method (FEM), shear behaviour of carbon fabric prepreg, which is made of carbon plain fabric and pre-consolidated epoxy resin, is studied at meso-level. According to the geometrical characteristics of the carbon fabric prepreg, a 3D unit cell model of woven fabric is established and the meso-mechanism of deformation is modelled by FEM. In simulation, the periodic boundary conditions are adopted and the viscous resin is characterized by the friction between yarns. The relationship of shear force and shear angle is obtained by FEM simulation and the results show that shear force increases significantly when shear angle is up to a certain value. The validity of FEM simulation results is verified by a picture-frame test.

Keywords: Shear behaviour, Carbon fabric prepreg, Unit cell, Finite element method, Picture-frame test.

\section{INTRODUCTION}

Fabric prepreg is a kind of pre-impregnated woven textiles, in which the resin matrix is pre-consolidated ${ }^{1}$. As the resin matrix is pre-consolidated (Fig. 1), yarns can rotate at intersections as prepreg is under shear deformation, therefore, fabric prepreg has large shear deformation characteristic as pure fabric. The main objective of the paper is to study the large shear deformation of fabric prepreg by FEM and pictureframe test. A 3D unit cell model is established with the periodic boundary conditions adopted. The viscous resin is characterized by the friction between yarns. The relationship between shear force and shear angle is obtained by FEM simulation and picture-frame test and the in-plane shear mechanism is discussed.

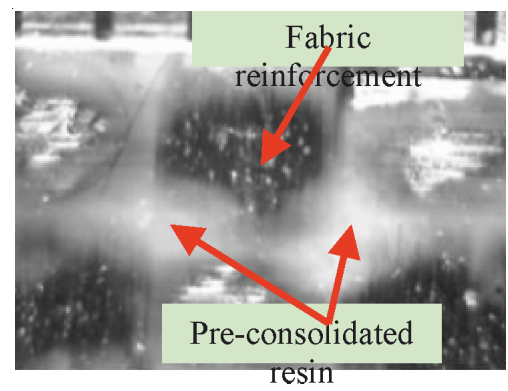

Fig. 1. Carbon fabric prepreg

\section{EXPERIMENTAL}

\section{Shear deformation simulation of unit cell by FEM}

Geometric model of unit cell: The unit cell is the basic structure of fabric, therefore, research on the mesoscopic constitutive of the fabric is usually based on unit cells. Mesoscopic parameters of unit cell mainly include fabric thickness, the length of unit cell, width of yarns, yarn sectional shape, yarn curve, the friction coefficient between yarns and so on. Among the parameters, the yarn sectional shape has been studied widely $^{2-4}$. Potluri and Thammandra ${ }^{5}$ and Boisse et al. ${ }^{6}$ proposed unit cell model with lenticular sectional of yarn to analyze biaxial and shear behaviour of glass plain woven fabrics. Lin et $a l^{7}$ adopted unit cell model with elliptic sectional of yarn to study shear mechanical behaviour of woven fabrics. Komeili and Milani ${ }^{8}$ studied biaxial tensile, shear and tension-shear coupling behaviour of woven fabrics based on a new unit cell model in which yarn curve and yarn sectional shape are sine curves. In this work, the yarn's section is treated as lenticular lens. Fig. 2 shows the 3D model of unit cell created by ABAQUS finite element software.

Boundary conditions, material modelling and contact conditions: Accurate boundary condition is required to get the accurate mesoscopic mechanical response. For unit cells, the adjacent boundary should satisfy continuity conditions of stress and strain. According to some researches, using boundary 


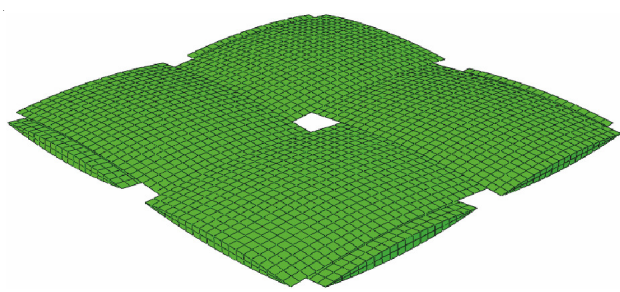

Fig. 2. 3D model used in FEM simulation

conditions such as equal stress and equal strain on unit cell model cannot get accurate simulation results ${ }^{9}$, so researchers tend to use periodic boundary conditions and more reliable mesoscopic mechanical response is obtained ${ }^{8,10}$. Suquet ${ }^{11}$ proposed a displacement field of unit cell, which can be expressed as

$$
\mathrm{u}_{\mathrm{i}}\left(\mathrm{x}_{1}, \mathrm{x}_{2}, \mathrm{x}_{3}\right)=\bar{\varepsilon}_{\mathrm{ik}} \mathrm{x}_{\mathrm{k}}+\mathrm{u}_{\mathrm{i}}^{*}\left(\mathrm{x}_{1}, \mathrm{x}_{2}, \mathrm{x}_{3}\right)
$$

where $\mathrm{x}_{\mathrm{k}}$ is any point in the unit cell, $\mathrm{u}_{\mathrm{i}}^{*}$ is the revised displacement and $\bar{\varepsilon}_{\mathrm{ik}}$ is the average strains of the unit cell. Obviously, eqn. 1 satisfies continuity conditions of displacement, but it cannot be applied in FEM simulation directly, because $\mathrm{u}_{\mathrm{i}}{ }^{*}$ is unknown. Xia et al. ${ }^{12}$ proposed that the periodic boundary conditions of unit cell with parallel boundaries can be written as

$$
\begin{aligned}
& u_{i}^{j+}=\bar{\varepsilon}_{i k} x_{k}^{j++}+u_{i}^{*} \\
& u_{i}^{j-}=\bar{\varepsilon}_{i k} x_{k}^{j-}+u_{i}^{*}
\end{aligned}
$$

where $u^{j+}{ }_{i}$ and $u_{1}^{j-}$ are displacements of parallel boundaries. Since $u_{i}{ }^{*}$ of parallel boundaries are identical, $u_{i}{ }^{*}$ can be eliminated as follow,

$$
u_{i}^{j+}-u_{i}^{j-}=\bar{\varepsilon}_{i k}\left(x_{k}^{j+}-x_{k}^{j-}\right)=\bar{\varepsilon}_{i k} \Delta x_{k}^{j}
$$

where $\Delta \mathrm{x}_{\mathrm{k}}{ }^{\mathrm{j}}$ is a constant, namely the length of the unit cell. Eqn. 4 can be applied in FEM simulation. Xia et al. ${ }^{13}$ further proved eqn. 4 satisfies the continuity conditions of stresses.

Mesoscopic numerical simulation of fabric prepreg is a complicated nonlinear process, which involves material nonlinearity, geometrical nonlinearity and boundary nonlinearity ${ }^{14}$. The material parameters of yarn depend on fiber distribution in yarn, which leads to highly material nonlinear problems. In this paper, a transverse isotropic mechanical model of yarn is adopted and the cross section that perpendicular to the yarn axis is the transverse plane. The flexibility matrix of yarn can be expressed as eqn. 5 with nine elasticity constants.

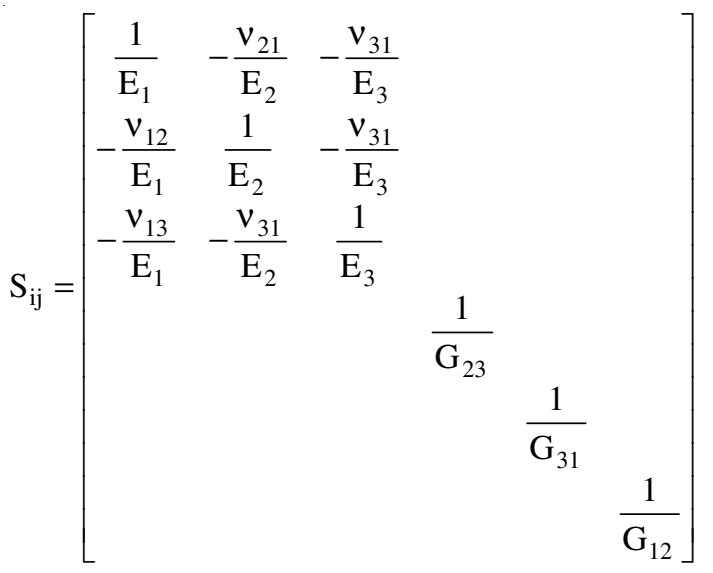

The axial direction of yarn is defined as direction 1 and direction 2 and direction 3 are the orthogonal directions in the transverse plane, hence $\mathrm{E}_{2}=\mathrm{E}_{3}, \mathrm{G}_{12}=\mathrm{G}_{13}, \mathrm{v}_{12}=\mathrm{v}_{13}$. There are $\mathrm{E}_{1} 164.32 \mathrm{GPa}, \mathrm{E}_{2}=\mathrm{E}_{3}=6.39 \mathrm{GPa}, \mathrm{G}_{12}=\mathrm{G}_{13}=15.14 \mathrm{GPa}$, $\mathrm{G}_{23}=5.55 \mathrm{GPa}, \mathrm{v}_{12}=\mathrm{v}_{13}=0.286, \mathrm{v}_{23}=0.366$.

As warp and weft have the same material parameters in this work, the master surface and the slave surface cannot be determined in ABAQUS, so the contact properties between yarns is set as "General contact". The viscous resin is characterized by the friction between yarns and equivalent friction coefficient of fabric prepreg is set as 0.26 here. Eqn. 4 given by Xia et al. ${ }^{12}$ can be applied easily in the unit cell model.

Picture-frame test: Picture-frame test is commonly-used methods to test the shear behaviour of woven fabric and other sheet materials ${ }^{15,16}$. The picture-frame test fixture is made of four rigid rods, where any fabric prepreg edge is clamped by two clamping chuckings and one clamping plate. In order to reduce friction, rigid rods are connected by rolling bearing [Fig. 3(a)]. Two opposing corners is installed on a tensile test machine and the distance between them is increased with the aid of the tensile testing machine and therefore sample shear is performed.

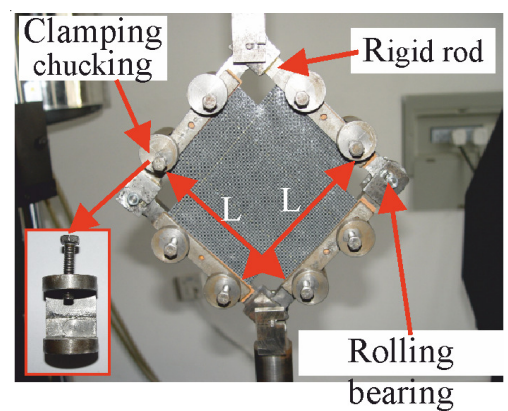

(a)

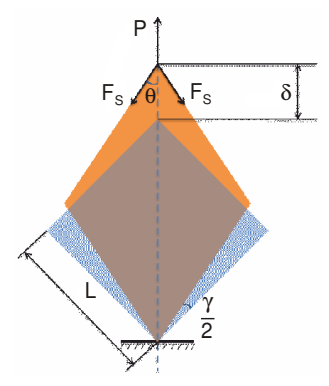

(b)
Fig. 3. Picture-frame test (a) test devise; (b) shear deformation sketch of fabric prepreg

The tensile test machine used in the experiment is Instron 5569 and the loading speed is $30 \mathrm{~mm} / \mathrm{min}$. A $500 \mathrm{~N}$ load cell with $0.004 \%$ tolerance is used and displacement sensor's accuracy is $\pm 0.02 \mathrm{~mm}$. In Fig. 3(b), $\gamma$ is shear angle, $\theta$ is the angle between rigid rod and the tensile axis, $\mathrm{L}$ is the length of rigid $\operatorname{rod}(\mathrm{L}=135 \mathrm{~mm})$ and $F_{\mathrm{s}}$ is the shear force which is parallel with the rigid rod. The displacement $\delta$ and load $\mathrm{P}$ can be measured at the crosshead. According to the geometric relationships, the relation between $\gamma$ and $\delta$ can be expressed as eqns. 6 and 7.

$$
\begin{gathered}
\cos \theta=\frac{\delta}{(2 \mathrm{~L})}+\cos \left(\frac{\pi}{4}\right) \\
\gamma=\frac{\pi}{2}-2 \theta
\end{gathered}
$$

The carbon fabric prepreg studied in the paper is made of balanced plain woven fabric and pre-consolidated epoxy resin. Table-1 shows parameters of the fabric prepreg for test. As warp and weft of the fabric prepreg have equivalent physical and mechanical properties, the yarn gap is regarded as a square. The specimens is the same size as the frame except for $25 \mathrm{~mm}$ $\times 25 \mathrm{~mm}$ patches that were cut from the four corners to allow free motion of the frame without wrinkling the fabric. 
TABLE-1

PARAMETERS OF THE FABRIC PREPREG FOR TEST

$\begin{array}{cccc}\text { Weight }\left(\mathrm{g} / \mathrm{cm}^{2}\right) & 420 \pm 20 & \text { Gap between yarns }(\mathrm{mm}) & 0.31 \\ \text { Width of yarn }(\mathrm{mm}) & 1.70 & \text { Thickness of yarn }(\mathrm{mm}) & 0.11 \\ \text { Yarn number } & 44 \times 44 & \text { Thickness of fabric } & 0.22 \\ & & \text { prepreg }(\mathrm{mm}) & \\ & & \end{array}$

Fig. 4 shows a typical shear force and shear angle curve obtained from the picture-frame test. It is observed that the shear deformation can be divided into two stages based on different shear mechanisms, namely shear stage and yarn lateral compression stage. The demarcation point is the fabric shear lock angle which can be determined by the unit cell model or experiment. Before the shear lock angle, the shear force increases slowly with the shear angle and yarn contact area at intersections increases and the rotation friction of yarns are the mainly mechanism to resist shear deformation. The shear force and shear angle curve is nonlinear obviously in the shear stage. When the shear angle reach the fabric shear lock angle, $22.5^{\circ}$ in the experiment, the adjacent yarns begin to contact and compression is happened and lateral compression of yarns are the mainly mechanism to resist shear deformation in this stage. The shear force and shear angle curve are approximately linear in the yarn extrusion stage.

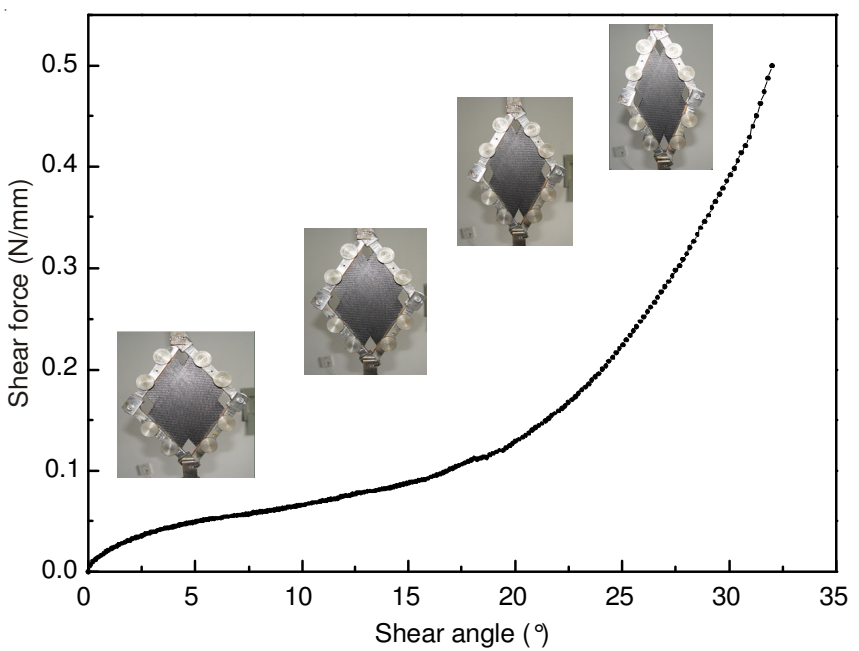

Fig. 4. Curve of shear force and shear angle

\section{RESULTS AND DISCUSSION}

The deformation of unit cell predicted by FEM simulation is shown in Fig. 5. It is found that yarn rotation is the main mechanism of fabric prepreg shear deformation. Fig. 6 is the shear force and shear angle curves of fabric prepreg obtained by FEM and experiment. It can be seen that the FEM simulation results coincide well with the experimental results when the shear angle is beyond $15^{\circ}$ and the maximum relative error is less than $10 \%$. However, when the shear angle is small, the shear force obtained by FEM is lower than that from experiment and the maximum relative error is nearly $70 \%$. This is because at the beginning of shear, extra load is required to make the pre-consolidated resin in the fabric gap to flow (Fig. 1), while in the finite element simulation, the pre-consolidated resin in the fabric gap is not considered, as a result, the FEM results is lower than that from experiment. As the shear angle increases, the pre-consolidated resin in the fabric gap is gradually

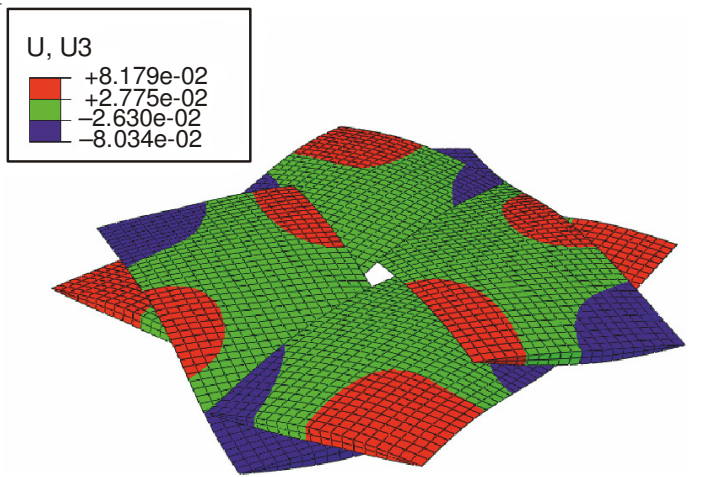

Fig. 5. Shear deformation of unit cell

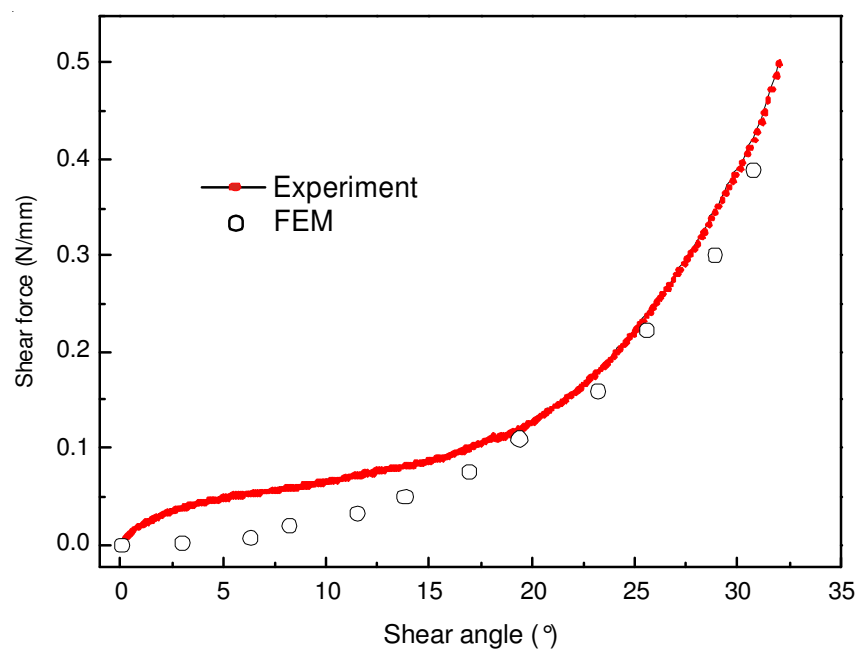

Fig. 6. Shear force and shear angle curves of fabric prepreg obtained by FEM and experiment

squeezed out, the FEM results begin to match the experimental results.

\section{Conclusion}

The shear deformation of carbon fabric prepreg is studied by finite element method at the meso-level and picture-frame test. A 3D unit cell model of fabric is established with periodic boundary conditions and the viscous resin is characterized by the friction between yarns. It is observed that yarn rotation and lateral compaction are two major deformation mechanisms of fabric prepreg under in-plane shear. The FEM results is compared with picture-frame shear test. It is observed that when the shear angle is smaller than the sheer lock angle, the pre-consolidated resin in the fabric gaps has significant on the shear behaviour of fabric prepreg, extra load is needed to squeeze out the, which is the main reason that shear fore obtained by FEM is lower than that by picture-frame experiment, because the pre-consolidated resin in the fabric gap is not consider in the FEM. However, when the shear angle is beyond $15^{\circ}$, nearly all the pre-consolidated resin in the fabric gap is squeezed out, the results of FEM coincide well with the picture-frame test results. In the future research, the preconsolidated resin in the fabric gaps will be considered in FEM.

\section{ACKNOWLEDGEMENTS}

The authors thank National Key Laboratory Fund (9140C490208130C49001) for support to this work. 


\section{REFERENCES}

1. A.A. Skordos, C. Monroy Aceves and M.P.F. Sutcliffe, Composites Part A, 38, 1318 (2007).

2. J. Peirce, J. Textil. Inst., 28, 3 (1937)

3. M. Tarfaoui and S. Akesbi, Colloids Surf. A, 187-188, 439 (2001).

4. C.G. Provatidis, S.G. Vassiliadis and E.A. Anastasiadou, Int. J. Cloth. Sci. Technol., 17, 29 (2005).

5. P. Potluri and V.S. Thammandra, Compos. Struct., 77, 405 (2007)

6. P. Boisse, A. Gasser, B. Hagege and J.-L. Billoet, J. Mater. Sci., 40, 5955 (2005).

7. H. Lin, M.J. Clifford, A.C. Long and M. Sherburn, Model. Simul. Mater. Sci. Eng., 17, 015008 (2009).
8. M. Komeili and A.S. Milani, Adv. Modern Woven Fabrics Technol., 13, 65 (2011)

9. M. Hori and S. Nemat-Nasser, Mech. Mater., 31, 667 (1999).

10. H. Sekine and S. Atobe, Compos. Struct., 89, 1 (2009).

11. P. Suquet, Homogeniz. Techn. Compos. Media, 272, 193 (1987).

12. Z.H. Xia, Y.F. Zhang and F. Ellyin, Int. J. Solids Struct., 40, 1907 (2003)

13. Z.H. Xia, C.W. Zhou, Q.L. Yong and X.W. Wang, Int. J. Solids Struct., 43, 266 (2006).

14. M. Komeili and A.S. Milani, J. Compos. Mater., 47, 2331 (2013).

15. D.J. Zhu, B. Mobasher, A. Vaidya and S.D. Rajan, Compos. Sci. Technol., 74, 121 (2013).

16. G. Cricrì, M. Perrella and C. Calì, Strain, 50, 208 (2014). 